on light/heavy water mixtures, containing 44, 62 and 87 per cent of heavy water, showed strictly additive susceptibility, $\mathrm{H}_{2} \mathrm{O}, \mathrm{D}_{2} \mathrm{O}$ and $\mathrm{HDO}$ therefore appear to have identical molecular diamagnetisms, and to have no influence on one another's magnetism.

J. H. Cruickshank, however, has carried out a more refined measurement, and noticed a peculiar lag in which appears an observable magnetic difference between the two waters. The change in susceptibility of freshly melted water, the temperature of which had been allowed to rise to that of the balance, $18^{\circ} \mathrm{C}$., was followed over a period of 30 minutes after melting by continuously reading the deflexions. The readings gradually increased to a maximum at 20 minutes after melting, and then fell slightly to a constant value.

According to recent views $\mathrm{s}^{3,4}$, the state of coordination of water is such that the molecules are, for geometric reasons, held farther apart than they would be in a state of closest packing. Therefore, although the local effect of co-ordination is to lower the diamagnetism at the bonds, the volume effect prevents depression at other points and keeps the diamagnetism up. In ice, co-ordination is a maximum ; in freshly melted water, there is a lag in deco-ordination shown by a continuous change in the susceptibility. This change is an increase to begin with, because the deco-ordination local effect (with its rise of diamagnetism) is predominant. Later, the corresponding volume effect (with its fall of diamagnetism) becomes more effective, as seen in the development of a maximum value.

In heavy water, both the increase in susceptibility to the maximum value and the subsequent fall to constant value are less than in light water, but take place in the same time. Deco-ordination in heavy water tends to take place less readily than in light; but the higher degree of co-ordination in the equilibrium state, and the accelerating effect on decoordination of the higher initial temperature, $3 \cdot 8^{\circ} \mathrm{C}$., counteract this tendency, with the result that equilibrium is reached in the same time as for light water. The rise to and the fall from the maximum susceptibility are less because the total loss of coordination required to reach equilibrium is less and thus there is less scope for display of lag.

It has been assumed that the temperature of the water rose to $18^{\circ} \mathrm{C}$. before the observations were begun, but the rise in susceptibility due to a still rising temperature requires to be added to the rise in susceptibility due to the local effect of decoordination. This makes the rise to the maximum greater than the fall to the equilibrium.

During an ordinary determination of susceptibility, the lag described here escapes observation because it is finished long before the constant can be determined.

The same experiment was tried with benzene m.p. $5 \cdot 4^{\circ}$ and aniline m.p. $-8^{\circ}$, but in neither case was a maximum observed, although it could be seen repeatedly with the waters.

Francis W. Gray.

James H. CRuickshank.

Department of Chemistry,

University, Aberdeen. Dec. 17.

${ }^{1}$ Selwood and Frost, J. Amer. Chem. Soc., 55, 4335; 1933.

2 Cabrera and Fahlenbrach, Naturwissenschaften, 22, 417 ; 1934.

3 Bernal and Fowler, J. Chem. Phys., 1, 515-548; 1933

‘ R. H. Fowler, Proc. Cam. Phil. Soc., 30, 225-241; 1934.

\section{Spectrum of Doubly Ionised Iodine}

Work on the identification of the lines belonging to this spectrum was begun more than four years ago and a preliminary announcement on a clue obtained which was expected to lead to an analysis of the spectrum was made at the time in these columns ${ }^{1}$. That clue, however, did not lead to the expected result, and had to be abandoned. Finally, it was realised that the only way of solution, though necessarily a very lengthy and tedious one, was to find all possible differences between the wavenumbers ascribed to this spectrum.

For this purpose the measurements made by Kerris $^{2}$ were used and, confining the frequency differences up to within about 15,500 , nearly 35,000 subtractions were effected. From these has been sorted out what is believed to be a genuine regularity among 50 lines of the spectrum. The agreement among the various differences occurring in this intercombination is of the order of $0 \cdot 2$. This has led to the identification of most of the terms in the $6 s$ and $6 p$ levels and a few in the $5 d$ level. The relative values of the terms are :-

$6 p$ level : $0,68 \cdot 5,1731 \cdot 0,2790 \cdot 7,4851 \cdot 0,5071 \cdot 4$, $6587 \cdot 1,8193 \cdot 7,10965 \cdot 2,12988 \cdot 9$.

$6 s$ level : $28222 \cdot 3,29630 \cdot 3,29908 \cdot 9,30272 \cdot 0$, $30503 \cdot 0,32839 \cdot 7,35299 \cdot 4$.

$5 d$ level : $24618 \cdot 6,27004 \cdot 7,40686 \cdot 6$.

Details of the work up to date are being sent for publication in the Indian Journal of Physics.

Physics Laboratory,

J. B. SeTh.

Government College, Lahore.

Dec. 24 .

${ }^{1}$ NATURE, 127,$165 ; 1931$

Z. Phys., 60, 20; 1930.

'Viscacelle' as a Material for making Compensating Plates and Wedges for the Polarising Microscope

'Vrscacelce' (cellulose sheet manufactured by Messrs. Courtaulds by the viscose process and used extensively as a wrapping material) is birefringent. There seems little doubt that this property is due to a net orientation of the long cellulose molecules caused by the unidirectional tension to which the sheet is subjected while being 'spun'. Under this tension, the molecules may be expected to arrange themselves so that their length directions are parallel or nearly parallel to the direction of tension. This explanation is supported by the fact that the direction of tension (revealed on cut sheets by parallel streaks) is the 'slow' direction of vibration.

The accompanying table gives some relevant

\begin{tabular}{|c|c|c|}
\hline $\begin{array}{l}\text { Manufacturer's } \\
\text { Classification }\end{array}$ & $\begin{array}{l}\text { Thickness } \\
(\mathrm{mm} .)\end{array}$ & $\begin{array}{l}\text { Polarisation Colour and } \\
\text { Relative Retardation }(\mathrm{m} \mu)\end{array}$ \\
\hline $\begin{array}{l}300 \text { Ordinary, Grade } 1 \\
300 \text { Ordinary, Grade } 2 \\
400 \text { Ordinary, Grade } 1 \\
600 \text { Ordinary, Grade } 1 \\
300 \text { Moistureproof, Grade } 1\end{array}$ & $\begin{array}{l}0.020-0.025 \\
0.020-0.025 \\
0.025-0.030 \\
0.040-0.045 \\
0.020-0.025\end{array}$ & $\begin{array}{lr}\text { (3 layers) purplish red, } & \text { c. } 575 \\
\text { (3 layers) orange red, } 450-480 \\
\text { (3 layers) bright blue, } & c .650 \\
\text { (1 layer) pale yellow, } & 300-340 \\
\text { (2 layers) bright blue, } & c .650 \\
\text { (3 layers) bright blue, } & c .650\end{array}$ \\
\hline
\end{tabular}

properties of specimens of different grades of 'Viscacelle' supplied by Messrs. Courtaulds. The relative retardations were deduced from the polarisation colours by means of Lévy's colour chart of birefringences. 